\title{
An Empirical Validation of Excellent Work Culture Scales: Evidence from Selected Established Higher Education Institutions in West Malaysia
}

\author{
Mohammed Borhandden Musah ${ }^{1}$, Hairuddin Mohd Ali ${ }^{2}$, Shafeeq Hussain Vazhathodi Al-Hudawi ${ }^{1}$ \& Abdul \\ Rahim bin Hamdan ${ }^{1}$ \\ ${ }^{1}$ Faculty of Education in Universiti Teknologi Malaysia, Johor Bahru, Malaysia \\ ${ }^{2}$ Faculty of Education, International Islamic University Malaysia, Kuala Luppur, Malaysia \\ Correspondence: Mohammed Borhandden Musah, Faculty of Education, Universiti Teknologi Malaysia, Skudai, \\ 81310, Johor Bahru, Malaysia. Tel: 60-19-308-0357. E-mail: borhandden@utm.my
}

Received: July 3, 2014 Accepted: August 12, 2014 Online Published: September 29, 2014

doi:10.5539/ass.v10n19p96

URL: http://dx.doi.org/10.5539/ass.v10n19p96

\begin{abstract}
This study argues that the components of excellent work culture (EWC) since its emergence in the 1980s in the Malaysian public sector were not empirically validated. Therefore, the purpose of this empirical study is to validate instrument and the factor structure of the underlying dimensions of EWC in higher education institutions (HEIs) in West Malaysia. The study sampled 1068 faculty members of eight selected HEIs. The results reveal that the EWC two-factor model fitted the observed data; $\mathrm{CFI}=.97, \mathrm{TLI}=.97, \mathrm{NFI}=.97, \chi^{2} / d f=4.92, \mathrm{RMSEA}=.08$ and $\mathrm{SRMR}=.01$. Moreover, the results provide psychometric evidence of composite reliability, convergent and discriminant validity of the instrument validated. This study is deemed as an initiative in validating the psychometric properties of the scales. Theoretically, the study has marked a new direction in the positive work culture settings by devising empirical quantitative measures adding to the conceptual body of EWC. Practically, the findings have practical implications for policy makers in the education sector, both public and private with particular reference to establishing a more conducive work environment, which helps workforce performance and productivity at tertiary level to coexist effectively.
\end{abstract}

Keywords: construct validity, content validity, excellent work culture, higher education institutions

\section{Introduction}

The pursuit of excellence is an ongoing human endeavour. The search for quality and excellence is a moving, [and] never ending effort (Mahathir, 1984). Excellence features in business, manufacturing and educational organizations. Among many elusive variables such as diligence, commitment, seriousness, and effective management, one of the promising variable considered by flourishing businesses, manufacturing and educational organizations is excellent work culture (EWC). EWC contributes to achieving the desired workforce performance. In Malaysia, the concept of EWC appeared in 1980s, and since then was considered for the public sector reform initiatives. This study, therefore explores the psychometric properties of EWC from the context of Higher Education Institutions (HEIs) in West Malaysia.

\subsection{Context of the Study}

Higher education institutions in Malaysia have witnessed a rapid growth. At the time of independence in 1957, there was only one HEI in the peninsula (Ministry of Education Malaysia [MOE], 2001). As of now, there are 69 HEIs providing tertiary education (Malaysia University Portal [MUP], 2014). They are categorised into three; 18 public institutions, 43 private institutions, and 8 university colleges (MUP, 2014). Of the 18 public HEIs, this study sampled eight universities established for more than 25 years, i.e., International Islamic University Malaysia (IIUM), Universiti Teknologi Malaysia (UTM), Universiti Putra Malaysia (UPM), Universiti Malaya (UM), Universiti Kabangsaan Malaysia (UKM), Universiti Teknologi Mara (UiTM), Universiti Sain Malaysia (USM), and Universiti Utara Malaysia (UUM).

Given the historical development of HEIs sampled in this study, UM is considered the oldest university in the peninsula. It was set up as a medical college called King Edward VII college in 1905. In 1929 it was named as 
the Universiti of Malaya (Education Planning and Research Division [EPRD], 2001). As of now, UM constitutes 12 faculties in various disciplines, providing both undergraduate and postgraduate degrees. In the year 2012 when the data was collected, there were about 3057 academic staff at UM.

The second university, namely UTM started operation as a technical school in 1904 . The school was then upgraded to Technical College in 1941 (EPRD, 2001). The college was then upgraded in 1973 to become what is known now as UTM. The main campus of UTM in Johor Bahru comprises 14 faculties and graduate schools offering both undergraduate and postgraduate degrees in various disciplines. There was a population of 1500 academic staff serving in UTM when data was collected.

The third university is UKM, which was established in 1970 to uphold the Malay language as a language of knowledge and provides tertiary education to Malaysian citizens. Recommendations of a Malay committee of intellectuals gave birth to UKM in the stream of HEIs in Selangor (EPRD, 2001). UKM comprises 13 faculties providing both undergraduate and postgraduate degrees. As of the data collection time, there was 2237 academic staff in UKM.

The fourth university is UPM, which began as a School of Agriculture in 1931 in Selangor. It was then upgraded to become College of Agriculture Malaya in 1947. The college was then named as Universiti Pertanian Malaysia [Agriculture University of Malaysia] in 1971. It was finally labelled as Universiti Putra Malaysia in 1997. UPM comprises 16 faculties offering both undergraduate and postgraduate degrees. The population of academic staff in UPM at the time of data collection reached 1572 (EPRD, 2001; UPM, 2006).

The fifth university is USM, which was set up in Penang, north-west of Peninsular Malaysia in 1969, with a purpose of offering tertiary education to the communities of the northern peninsula (EPRD, 2001; USM, 2005). USM comprises 15 graduate schools offering both undergraduate and postgraduate degrees. There was 1782 academic staff employed in USM when the data was collected.

The sixth university is IIUM, which was established in 1983, with the aim of catering for the educational needs of both Malaysians and other Muslims across the globe. The establishment of IIUM was inspired by the recommendations of the first World Conference on Muslim Education held in Mecca, Saudi Arabia in 1977. There are 14 faculties and institutes in IIUM offering graduate and postgraduate degrees in various educational spheres. There was about 1904 academic staff employed in IIUM when data was collected.

The seventh university is UiTM, which is located in Shah Alam, Selangor. UiTM started operations in 1956 as a training centre. In 1965, the centre was upgraded to a college, and henceforth to an institute in 1967 (EPRD, 2001; UiTM, 2005). The institute was upgraded to become what is known as UiTM in 1999. UiTM comprises 24 faculties offering both undergraduate and postgraduate degrees in various disciplines. As of the time when data was collected, there was 4000 academic staff employed in UiTM.

The final university is UUM, situated in Sintok Kedah, the northern part of the peninsular. UUM was established in 1984, with specific focus on management, business administration and information technology (EPRD, 2001). UUM consists of 13 faculties offering undergraduate and postgraduate degrees in various disciplines. There was 1396 academic staff in UUM when the data was collected.

\subsection{Excellent Work Culture}

The concept of EWC was introduced in the Malaysian public sector in 1980s aiming its reform. The focus was particularly on civil servants, thus "the need for changing the attitude of civil servants continued to be made throughout the 1980s by top government politicians" (Mahathir, 1984, p. 193). Precisely, from 1991 the government of Malaysia instructed through a pekeliling kemajuan perkhidmat anawam, 'PKPA' [civil service development circular] that every government agency should regulate the quality of work culture on the daily basis (Hamzah, Sin \& Abdullah, 2009; Khaliq, 2001; Siddiquee, 2007).

It is worth noting that EWC cannot be adequately materialised overnight through a traditional approach. Rather, it is realised through careful planning, deliberate effort and active commitment over a prolonged time frame. That is to say EWC as a culture develops across a set of identity-based values within two distinct yet closely interrelated systems, namely, a religious system basing its authority on the Islamic notion of allegedly universal values and an anthropological system basing its authority on scientific examination of local cultural values (Triantafillou, 2002). In other words, when EWC becomes the core of any organizational culture, be it in manufacturing, business or educational, certain values develop within these two systems (Hamzah, et al., 2009), which are identified as two independent factors of EWC (Triantafillou, 2002; Musah, 2013). 
Thus, theoretically it is argued that values such as diligence, commitment, seriousness, sense of accountability are critical to any given organizational performance. However, it will be vain unless EWC is translated into the practical levels as core culture in the organizational settings.

But, applying EWC through quantitative means is yet studied. To capture the nature of the issue, studies on EWC were tabulated given a criterion of inclusion and exclusion. The tabulation shows five related studies in which variables such as public sector, contents constituted EWC, public service, local values, innovation, policy transfer and public management were investigated. Appendix 1 displays studies conducted on EWC related dimensions.

Given the methods used in these five studies, it is evident that all five studies used a conceptual technique to investigate the variable. Thus, the tabulation did not come about any empirical work done in validating EWC instrument. This phenomenon in EWC studies has pinpointed the need for conducting an empirical study. Meanwhile, in most instances the conceptual technique often neglects the practical aspect of the investigated phenomenon. As such, this study aims at examining the underlying factors of EWC and validates instrument constituted EWC factors in the context of selected eight established HEIs in West Malaysia.

The absence of empirical studies on EWC, hints the need to evaluate the validity and reliability of EWC scale quantitatively. Assuring scale validity and reliability is particularly important. It has been argued that an instrument should hold evidence of both construct reliability and validity of any given conceptualised component if the findings were to reach accurate and sound conclusions (Hallinger, Wang, \& Chen, 2013). Therefore, the study puts forward the following research questions and hypotheses:

Research question 1: What are the underlying factors of EWC in the context of selected Malaysian HEIs?

Research hypothesis 1: EWC is a two-factor model in the context of selected Malaysian HEIs.

Research question 2: Are the factors of EWC in the context of Malaysian HEIs valid and reliable?

Research hypothesis 2: Factors of EWC in the context of Malaysian HEIs are valid and reliable.

Exploratory factor analysis (EFA) was initially used to investigate the factor structure of EWC and answer the two research questions. Confirmatory factor analysis (CFA) was then used to test the two research hypotheses about construct and discriminant validity of EWC factors indexed through the application of EFA.

\section{Content Validity}

The researchers conducted content validity prior to data collection to ensure that a detailed description of the content domain is captured. To perform this assessment, sixteen questionnaires were administered to quality managers and experts in the area of human resource management at the selected established HEIs. The participants were purposively selected and asked to respond to the survey questions. The selection of this particular group for this special task was due to the reason that they were more engaged in monitoring and improving quality programmes than the rest of the faculty members. Most of the respondents commented that item number 16 "My institution promotes righteousness among faculty members" is vague. The researchers then revised the item as "My institution values sense of the righteousness of its faculty members". Obtaining a sound instrument per se is not enough to generate concrete information from the respondents, but it should be equally assured that the instrument is valid and reliable given its construct. As such, rigorous analyses were further performed to assess the construct validity and reliability of the instrument.

\section{Methods}

\subsection{Sample}

A total of 1068 faculty members of selected HEIs was sampled and voluntarily participated in this study. The researchers personally distributed the survey questionnaires to a purposeful sample of faculty members in the selected HEIs in West Malaysia. Of 1068 survey questionnaires distributed, 702 were returned and therefore analysed. This accounted for $65.73 \%$ of response rate.

\subsection{Instrument}

The study used a survey questionnaire in the process of investigating the underlying structures and validating EWC instrument. Excluding the demographic information, the questionnaire consisted of 16 measures (Triantafillou, 2002) of which, 8 measures constituted the Islamic codes of self-conduct (ISC) factor and the other 8 measures comprised the anthropological objectification (AO) factor. The researchers constructed the measures of the EWC through extensive analysis of the related literature on EWC at different organizational settings. 
The questionnaire composes close-ended statements used in determining the measures of EWC that this research aimed to evaluate. Precisely, it comprises two major sections. Section one, formed four items, which requested respondents to provide general demographic information such as gender, race group, and the universities to which they are affiliated. Section two, comprises the two hypothesised factors with a total of 16 measures. A six-point Likert type scale was employed for data collection. The scale is interpreted as: $1=$ very strongly disagree, $2=$ strongly disagree, $3=$ disagree, $4=$ agree, $5=$ strongly agree and $6=$ very strongly agree.

In the process of examining the underlying structure of EWC hypothesised factors, the data was subjected to an EFA, through predictive analytics software (PASW) version 20.0. Furthermore, CFA was used through the application of analysis of movement structure (AMOS) software version 21.0 to confirm and validate the factors indexed through EFA.

The model fit was assessed based on several criteria. Specifically, standardized root-mean-square residual (SRMR) and root-mean-square error of approximation RMSEA (Steiger and Lind, 1980) were used to to correct the tendency of the model $\chi^{2}$ statistics to reject any specified model with a sufficient large sample (Hair et al., 2010). Values lower than .06 for the SRMR and lower than .08 for the RMSEA were used to determine a good-fitting model (Hu \& Bentler, 1999). Comparative Fit Index (CFI), Tucker-Lewis Index (TLI), and Normed Fit Index (NFI) were also used to assess the adequacy of the hypothesised model. A value of $\geq .90$ was considered as a representative of a well-fitting model (Byrne, 2010; Hair et al., 2010). In addition, CIMIN/DF $(\chi 2 / \mathrm{df})$, which addresses the minimum discrepancy divided by its degrees of freedom in model, was also used.

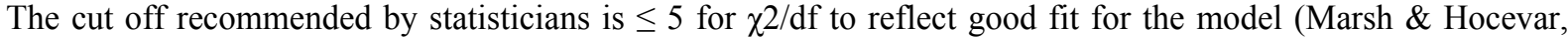
1985; Wheaton, 1987).

\section{Results}

\subsection{Descriptive Results}

The results of the frequencies indicate that $(\mathrm{n}=357,50.9 \%)$, of the respondents were male faculty members while $49.1 \%(\mathrm{n}=345)$ were female faculty members.

Interestingly, the analysis shows that the majority of the respondents $(\mathrm{n}=554,78.9 \%)$ were faculty members of Malay ethnic group. Furthermore, $(n=86,12.3 \%)$ were identified as foreign faculty members. While $(n=41,5.8 \%)$ Chinese faculty members participated in the study, only $3.0 \%(n=21)$ Indian faculty members responded to the survey questionnaire.

Table 1. Frequency and percentages of respondents' gender, race, university and religion

\begin{tabular}{lccc}
\hline \multirow{6}{*}{ Gender } & Variable & Frequency & \% \\
& Male & 357 & 50.9 \\
& Female & 345 & 49.1 \\
& Total & 702 & 100 \\
Race group & & \\
& Malay & 554 & 78.9 \\
& Chinese & 41 & 5.8 \\
& Indian & 24 & 3.0 \\
& Others & 86 & 12.3 \\
& Total & 702 & 100 \\
& & & \\
& UM & 92 & 13.1 \\
& UKM & 90 & 12.8 \\
& UPM & 99 & 14.1 \\
& UiTM & 42 & 6.0 \\
& UUM & 106 & 15.1 \\
& USM & 90 & 12.8 \\
& UTM & 107 & 15.2 \\
& IIUM & 76 & 10.8 \\
& Total & 702 & 100 \\
\hline
\end{tabular}

In addition, the responses of faculty members surveyed indicate that the majority $(n=107,15.2 \%)$ were from Universiti Teknologi Malaysia (UTM). Followed by Universiti Utara Malaysia (UUM) (n=106, 15.1\%). 
Followed by Universiti Putra Malaysia (UPM) ( $\mathrm{n}=99,14.1 \%)$. Followed by Universiti Malaya (UM) ( $\mathrm{n}=92$, 13.1\%). Followed by both Universiti Kebangsaan Malaysia (UKM) ( $\mathrm{n}=90,12.1 \%)$ and Universiti Sains Malaysia (USM) ( $n=90,12.1 \%)$. Then by International Islamic University Malaysia (IIUM) $(n=76,10.1 \%)$. Faculty members of UniversitiTeknologi Mara (UiTM) were classified as the least on the participation scale $(\mathrm{n}=42,6.0 \%)$. Table 1 , depicts the details.

Interestingly, the descriptive analysis revealed that means for all 16 measures were within reasonable limits. The standard deviations for all 16 measures were also observed to fall within reasonable limits. Furthermore, the minimum and maximum also exhibits reasonable values for each individual measure in the study. Skewness, kurtosis and item total correlation also demonstrate desired values. Table 2 describes the details.

Table 2. Descriptive statistics for each EWC measure

\begin{tabular}{cccccccc}
\hline Measure & Minimum & Maximum & Mean & $\begin{array}{c}\text { Std. } \\
\text { Deviation }\end{array}$ & Skewness & Kurtosis & $\begin{array}{c}\text { Corrected Item-Total } \\
\text { Correlation }\end{array}$ \\
\hline ICS1 & 1.00 & 6.00 & 4.2279 & .86089 & -.134 & .797 & .791 \\
ICS2 & 1.00 & 6.00 & 4.2336 & .89513 & -.261 & .824 & .851 \\
ICS3 & 1.00 & 6.00 & 4.2293 & .87122 & -.267 & .874 & .856 \\
ICS4 & 1.00 & 6.00 & 4.2293 & .86958 & -.292 & .925 & .841 \\
ICS5 & 1.00 & 6.00 & 4.2108 & .86853 & -.107 & .575 & .791 \\
ICS6 & 1.00 & 6.00 & 4.2379 & .87383 & -.237 & .847 & .860 \\
ICS7 & 1.00 & 6.00 & 4.2493 & .92159 & -.273 & .791 & .854 \\
ICS8 & 1.00 & 6.00 & 4.2350 & .89077 & -.381 & 1.287 & .826 \\
AO1 & 1.00 & 6.00 & 4.2977 & .86026 & -.290 & .825 & .753 \\
AO2 & 1.00 & 6.00 & 4.3319 & .86100 & -.265 & .867 & .759 \\
AO3 & 1.00 & 6.00 & 4.3048 & .85693 & -.042 & .215 & .785 \\
AO4 & 1.00 & 6.00 & 4.4031 & .82827 & -.052 & .499 & .785 \\
AO5 & 1.00 & 6.00 & 4.3219 & .84560 & -.283 & 1.075 & .833 \\
AO6 & 1.00 & 6.00 & 4.2094 & .89556 & -.208 & .323 & .791 \\
AO7 & 1.00 & 6.00 & 4.2108 & .83504 & -.029 & .580 & .762 \\
AO8 & 1.00 & 6.00 & 4.2621 & .89838 & .005 & .095 & .656 \\
\hline
\end{tabular}

\subsection{EWC Exploratory Factor Analysis}

An EFA with varimax rotation was performed to assess the underlying structure for the 16 measures of EWC in the questionnaire, and test alignment of the measures under the earlier hypothesised factors. The analysis generated two interpretable factors as hypothesised with eigenvalues greater than one.

The two factors accounted for $72.91 \%$ of the total variance explained, with a determinant score of 3.493 , which reflected the fulfilment of the assumption, that there no multicolliniarity issue with the measures. Moreover, the degree of inter-correlation among the measures also reached an acceptable level, Bartlett's Test of Sphericity was statistically significant, $\chi^{2}(105)=1011.61, \rho<.001, \mathrm{KMO}=.95$. The MSA, which asserted the correlation within the measures also ranged from .92 to .98 .

In addition, internal consistency analysis, which was employed using Cronbach's Alpha on each factor extracted through EFA showed that the factors composing the construct are reliable. The values of EWC two factors were .92 and .93 respectively. As such, the inclusion criterion was met.

To expatiate upon the two factors extracted, factor one, which labelled as Islamic codes of self-conduct, was indexed by eight measures, which were initially hypothesised on this factor. Seven measures were highly weighted on the hypothesised factor. However, one measure (ICS8) "the institutional spiritual principle establishes discipline at my workplace" was discarded due to the issue of factorial complexity on two factors. The loadings of the seven measures ranged from .59 to .84 indicating practical and statistical significance of the measures (Hair, Anderson, Tatham, \& Black, 2010).

Pertaining to the second factor, which also initially contained eight measures that represented anthropological objectification, all measures initially hypothesised on this factor, reasonably loaded on it. The loadings ranged from .60 to .80 indicating practical and statistical significance of the measures (Hair et al., 2010). 
Table 3. Excellent Work Culture Scale; Factor Loading, Anti Image, Means, Reliability, Variance Explained and Standard Deviation

\begin{tabular}{|c|c|c|c|c|c|c|}
\hline \multirow{2}{*}{ No. } & \multirow{2}{*}{ Measure } & \multicolumn{2}{|c|}{ Factor Loading } & \multirow{2}{*}{ MSA } & \multirow{2}{*}{ M } & \multirow{2}{*}{ SD } \\
\hline & & ICS & $\mathrm{AO}$ & & & \\
\hline ICS1 & $\begin{array}{l}\text { The institutional spiritual principle forms a sense of responsibility in my } \\
\text { workplace. }\end{array}$ & .84 & & .95 & 4.22 & .86 \\
\hline ICS 2 & $\begin{array}{l}\text { The institutional spiritual principle forms a sense of sincerity in my } \\
\text { workplace. }\end{array}$ & .83 & & .92 & 4.23 & .89 \\
\hline ICS 3 & $\begin{array}{l}\text { The institutional spiritual principle enhances the attitude of dedication at } \\
\text { my workplace. }\end{array}$ & .80 & & .93 & 4.22 & .87 \\
\hline ICS 4 & $\begin{array}{l}\text { The institutional spiritual principle develops an attitude of diligence at } \\
\text { my workplace. }\end{array}$ & .79 & & .96 & 4.22 & .86 \\
\hline ICS 5 & $\begin{array}{l}\text { The institutional spiritual principle enhances sense of cleanliness in my } \\
\text { workplace. }\end{array}$ & .78 & & .95 & 4.21 & .86 \\
\hline ICS6 & $\begin{array}{l}\text { The institutional spiritual principle enhances sense of cooperation at my } \\
\text { workplace. }\end{array}$ & .74 & & .98 & 4.29 & 1.36 \\
\hline ICS7 & $\begin{array}{l}\text { The institutional spiritual principle forms trustworthiness at my } \\
\text { workplace. }\end{array}$ & .59 & & .98 & 4.24 & .92 \\
\hline $\mathrm{AO} 1$ & My institution values collectivism for excellence. & & .80 & .98 & 4.29 & .86 \\
\hline $\mathrm{AO} 2$ & Faculty members of my institution hold respect for authority. & & .80 & .95 & 4.33 & .86 \\
\hline $\mathrm{AO} 3$ & My institution infuses a sense of tolerance among faculty members. & & .79 & .96 & 4.30 & .85 \\
\hline $\mathrm{AO} 4$ & $\begin{array}{l}\text { In my institution, mutual respect is equally encouraged among faculty } \\
\text { members. }\end{array}$ & & .76 & .95 & 4.40 & .82 \\
\hline $\mathrm{AO} 5$ & My institution values sense of righteousness of its faculty members. & & .75 & .96 & 4.32 & .84 \\
\hline AO6 & Sincerity is embodied in all activities of my institution. & & .74 & .96 & 4.20 & .89 \\
\hline $\mathrm{AO} 7$ & My institution empowers discretion among faculty members. & & .73 & .96 & 4.21 & .83 \\
\hline AO8 & My institution promotes generosity among faculty members. & & .60 & .97 & 4.26 & .89 \\
\hline \multicolumn{2}{|c|}{ Eigenvalues } & 9.80 & 1.15 & & & \\
\hline \multicolumn{2}{|c|}{ Construct Validity } & 72.25 & 70.57 & & & \\
\hline \multicolumn{2}{|c|}{ Construct Reliability } & .96 & .95 & & & \\
\hline
\end{tabular}

Factor loadings less than .50 were omitted and variables have been sorted by loading on each factor.

In addition, construct validity, which was employed using total variance explained by each factor in EWC construct showed that the two factors composing the EWC construct are valid $72.25 \%$ and $70.57 \%$ respectively. Table 3 depicts the details.

Furthermore, the examination of graphical scree plot also suggested a 2-factor solution. This result further provides evidence to the retained factors. Figure 1 depicts more details.

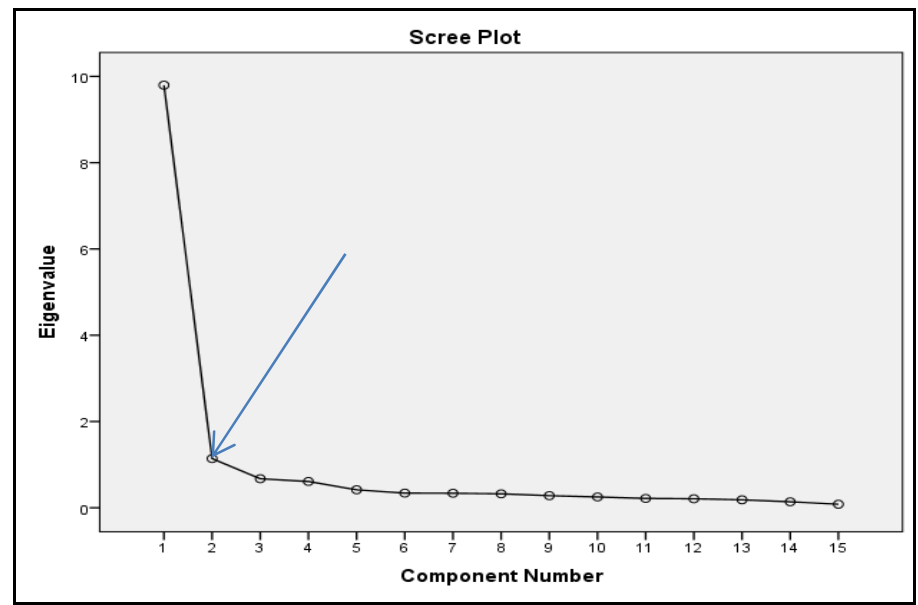

Figure 1. Scree plot of the rotated factors 


\subsection{Parallel Analysis (PA) of Excellent Work Culture Components}

An analysis of PA was performed on the EWC construct. The analysis revealed that the eigenvalues of the two factors extracted through EFA were greater than their corresponding eigenvalues of the PA, and are thus significant at $p=0.05$. Therefore, the two factors were retained for further interpretation. In other words, the decision failed to reject these two factors (Franklin, Gibson, Robertson, Pohlmann, \& Fralish, 1995; Horn, 1965; Pallant, 2007). This result further confirmed and cross validated the accuracy and reliability of the two factors extracted through EFA. Table 4 depicts the details.

Table 4. Comparison of EFA and PA eigenvalues for data from EWC construct

\begin{tabular}{cccc}
\hline Component no. & Actual eigenvalue from EFA & Criterion eigenvalue from PA & Decision \\
\hline 1 & 9.80 & 1.25 & Accept \\
2 & 1.15 & 1.02 & Accept \\
\hline
\end{tabular}

\section{Construct Validity}

\subsection{Validating EWC Measurement Model}

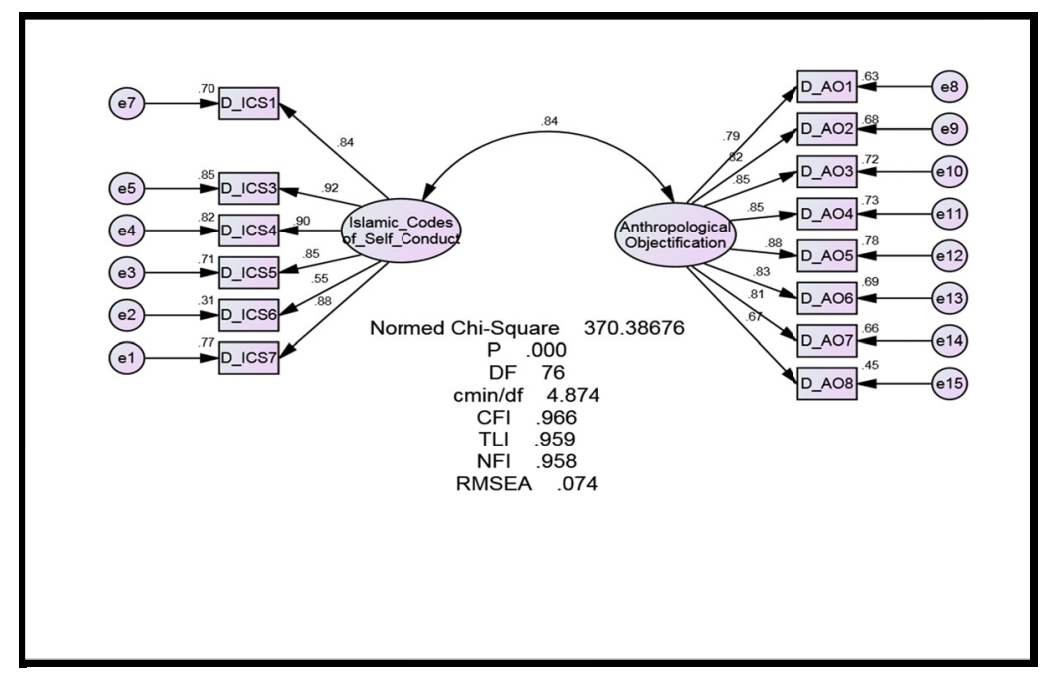

Figure 2. The generated output of revised of model of EWC

Table 5. Assessment of standardised regression weights through t-significance

\begin{tabular}{ccccc}
\hline Construct & Items & Standardized loading & $t$-value & Fit indices \\
\hline & ISC7 & .877 & 1.000 & \\
& ISC6 & .554 & $16.149^{* * *}$ & \\
& ISC5 & .845 & $30.662^{* * *}$ & \\
Islamic codes of & ISC4 & .904 & $35.237^{* * *}$ & \\
self-conduct & ISC3 & .922 & $36.877^{* * *}$ & $\chi^{2}=370.386$, \\
& ISC1 & .836 & $30.036^{* * *}$ & $\mathrm{df}=76$, \\
& AO1 & .792 & 1.000 & $\mathrm{p}=.001$, \\
& AO2 & .822 & $24.780^{* * *}$ & $\chi 2 / \mathrm{df}=4.874$ \\
& AO3 & .846 & $25.774^{* * *}$ & $\mathrm{CFI}=.96$, \\
Anthropological & AO4 & .852 & $26.017^{* * *}$ & $\mathrm{TLI}=.95$, \\
objectification & AO5 & .881 & $27.276^{* * *}$ & $\mathrm{NFI}=.95$, \\
& AO6 & .832 & $25.162^{* * *}$ & $\mathrm{RMESA}=0.07$ \\
& AO7 & .811 & $24.298^{* * *}$ & \\
\hline
\end{tabular}

Note: $* * *=\mathrm{p}$-value $<0.001 ; * *=\mathrm{p}$-value $<0.01 ; *=\mathrm{p}$-value $<0.05$ 
Fit indices of the measurement model demonstrate that the hypothesised model received a good fit to the sampled data: $\chi^{2}=535.4868, d f=89, \mathrm{CFI}=.95, \mathrm{TLI}=.94, \mathrm{NFI}=.94, \mathrm{RMSEA}=0.06$ and SRMR $=.02$. Furthermore, the squared multiple correlations (SMC), which indicate how well the observed variables serve as measures of the latent variables were also investigated. It is worth noting that the values of SMC of the EWC measurement model had met the criteria $\geq .25$ (Schumacker \& Lomax, 2004). The values ranged from .30 to .88. This provides substantial evidence of the reliability of the parameter estimates.

However, the value of $\chi^{2} / d f 6.01$ is greater than the accepted threshold of $\leq 5.0$ (Wheaton, Muthen, Alwin, \& Summers, 1977). Since the study sought a better fitting model, Post Hoc modification indices were investigated in order to identify a more parsimonious model. As such, the measurement model of EWC was re-estimated.

The investigation of MIs pinpointed that ICS2 was cross loaded with different error term. The measure was then dropped from the factor. Consequently, the model demonstrated good fit to the sampled data: $\chi^{2}=370.386, d f=$ $76, \mathrm{CFI}=.96, \mathrm{TLI}=.95, \mathrm{NFI}=.95, \chi^{2} / d f=4.87, \mathrm{SRMR}=.01$ and RMSEA $=0.07$. Furthermore, all values of critical rationality were above the cutoff score of 1.96. Figure 2 depicts the details. This result supported hypothesis 1 with the finding that EWC is a two-factor model in the context of eight selected HEIs in West Malaysian.

In addition, the study also examined the standardised loadings for the returned items by testing the critical ratio and significance of path coefficients. The results indicated that all $(t>1.96)$ for regression weights suggesting the adequacy of parameter estimates. All standardised parameter estimates were observed to be significant at $p$-value

.001. Table 5 depicts the details.

\subsection{Assessment of Discriminant Validity, Composite Reliability and Average Variance Extracted}

Given the instrument validation as the principal purpose of this study, the two factors of EWC were further rigorously evaluated using CRI, AVE and DV methods. Evidence of convergent and construct validity is obtained if the AVE is at least $\geq .50$ (Fornell \& Larcker, 1981). Furthermore, evidence of construct reliability is established if CRI of each factor is $\geq .70$ and AVE of each factor is $\geq .50$.

Interestingly, the results demonstrate that the measures are reasonably convergent on their respective factors. Meanwhile, all factors have exceeded the recommended threshold CRI of ( $\geq .70)$ and AVE of ( $\geq .50)$, indicating the attainment of construct validity. These results supported Hypothesis 2 with the finding that factors of EWC in the context of Malaysian HEIs are valid and reliable.

On the similar note, the results allow us to assess the extent to which measures of one construct are empirically distinct from each other (Bagozzi \& Burnkrant, 1985). This is to say, DV should be performed. According to Fornell and Larcker (1981), and Byrne (2010), in order to establish DV; (a) inter-factor correlations should be examined and; (b) squared correlation with the AVE value for each of the constructs should be compared.

The results show that the two factors, lack evidence of DV based on the squared inter-correlation obtained (.70) with AVE values obtained (.69 and .66). However, it has been stressed that if inter-correlations of a set of variables that are presumed to measure different factors are not too high $(\leq .85)$, evidence of DV is established (Kline, 2011). Simply put, evidence of DV could be hardly claimed if inter-correlation of two factors is ( $\geq .90)$ (Kline, 2011). In a nutshell, the measurement model demonstrates adequate reliability, convergent and DV validity. Table 6 demonstrates the details.

Table 6. Construct reliability and validity of the measurement models

\begin{tabular}{cccc}
\hline \multicolumn{4}{c}{ AVE, Squared inter-factor correlation and CRI } \\
\hline Construct & ICS & AO & CRI \\
ICS & $(.69)$ & & .93 \\
AO & .70 & $(.66)$ & .94 \\
\hline
\end{tabular}

Note. Diagonals in parentheses are square roots of the average variance extracted from observed variables (items), whereas off-diagonal is squared correlations between the factors.

\section{Discussion}

This study was designed to empirically fill a gap in the healthy work culture literature by evaluating the psychometric properties of EWC construct (Triantafillou, 2002), and provide quantitative measures of the scale for the equal use by both quality units of educational institutions and practitioners. Empirical evidence of the instrument was established through EFA and FCA statistical techniques, indicating the practical significance 
$(\geq \pm .50)$ in all EFA measure loadings and good fit statistics in CFA parameter estimates and fit indices. The psychometric evidence was further strengthened by the use of AVE and CRI assessments that advanced the validity and reliability of the factors evaluated.

More specifically, the findings establish preliminary quantitative measures and add to the research base related to the EWC conceptualisation, and as such, contribute to efforts of establishing a healthy work culture and performance measures for assessing work culture in HEIs and others.

Drawing on the results, it is clearly evident that the retained measures demonstrate high coefficients on their respective factors, signifying appropriateness and soundness of the instrument, with practical importance and statistical significance in the context of HEIs sampled.

The EFA and CFA analyses demonstrate, that EWC construct is a two-factor model; Islamic codes of self-conduct/spirituality and anthropological objectification. The proposed measurement model in this preliminary study was found to exhibit an acceptable fit statistics, thus lending further evidence for discriminant, convergent, and on the whole, the construct validity of the instrument.

In addition, the measures of EWC, which were empirically indexed to create a healthy work culture and reform public and private sectors in the institutional sector, were found to be all-encompassing instrument and thus could be used in future studies, especially in studying HEIs culture. Moreover, the instrument could be replicated in other Asian university context if the similarity of the cultural dimension is held.

\section{Implications of the Study}

Theoretically, the present study has yielded valid and reliable instrument for measuring EWC dimension at the tertiary level by conducting empirical analyses using survey data collected from faculty members of selected HEIs in West Malaysia. This instrument is suitable for Malaysian HEIs and other neighbouring countries taking the cultural aspect into consideration to investigate the nature of work culture in the institutional settings. The results added new body of knowledge to the healthy work culture other than the conceptual dimensions being studied. This is so due to the paucity of suitable quantitative measures of EWC in HEIs sector.

Furthermore, the findings have practical implications for policy makers in the education sector, both public and private with particular reference to establishing a more conducive work environment which helps workforce performance and productivity at tertiary level to coexist effectively. To be more specific, university top management and researchers may use the measures to investigate the nature of the institutional work environment.

\section{Limitations and Future Research Direction}

Despite the fact that, the findings, initiate preliminary and sound empirical measures associated with EWC construct, there were some limitations attributed to the study. The study sampled only eight established universities in West Malaysia, excluding Sabah and Sarawak. Adding to that, the study sampled only faculty members of the HEIs. There was no inclusion of administrative staff, students or support staff. Thus, the results should be interpreted with caution. This limitation suggests that future research in Malaysia should diversify participants (faculty members, administrative staff, students, and support staff) and include Sabah and Sarawak to capture comprehensive information of the concept across Malaysian multicultural HEIs.

\section{Conclusion}

This study represents a significant step in establishing preliminary empirical measures of EWC. The results provide reasonable evidence of validity and reliability of the EWC construct in the context of HEIs sampled in West Malaysia. The EWC factors demonstrated appropriate psychometric properties, exhibiting reliability, convergent validity, construct validity and discriminant validity across responses of faculty members participated in this study. Furthermore, the empirical measures of EWC fill a gap in research in that no empirical quantitative measures of the concept currently exist in relation to EWC literature. These preliminary empirical findings intrigue the need and pave the way for more studies to be carried out in replicating the measures validated in this study to establish appropriateness across cultures and HEIs could be finally claimed. This is an avenue that warrants further exploration of EWC construct.

\section{References}

Bagozzi, R. P., \& Burnkrant, R. E. (1985). Attitude organization and the attitude behaviour relation: A reply to Dilon and Kumar. Journal of Personality and Social Psychology, 49, 47-57.

Byrne, B. M. (2010). Structural equation modelling with AMOS; basic concepts, applications and programmes (2nd ed.). New York: Taylor and Francis Group. 
Education Planning and Research Division. (2001). Education in Malaysia: A journey to Excellence. Kuala Lumpur: Ministry of Education Malaysia.

Fornell, C., \& Larcker, D. F. (1981). Evaluating structural equation models with unobservable variables and measurement error. Journal of Marketing Research, 18(1), 39-50.

Franklin, S. B., Gibson, D. J., Robertson, P. A., Pohlmann, J. T., \& Fralish, J. S. (1995). Parallel analysis: A method for determining significant principal components. Journal of Vegetation Science, 6(1), 99-106. Retrieved from http://opensiuc.lib.siu.edu/pb_pubs/9

Hair, J. F., Back, W. C., Babin, B. J., Anderson, R. E., \& Tatham, R. L. (2010). Multivariate data analysis (7th ed.). New Jersey: Pearson Prentice Hall.

Hallinger, P., Wang, W. C., \& Chen, C. W. (2013). Assessing the measurement properties of the principal instructional management rating scale: A meta-analysis of reliability studies. Educational Administration Quarterly, 49(2), 272-309. http://dx.doi.org/10.1177/0013161X12468149

Hamzah, M.S., Sin, I., \& Abdullah, S. K. (2009). Leadership in the creation of excellent work culture. European Journal of Social Sciences, 10(4), 528-538.

Horn, J. L. (1965). A rationale and test for the number of factors in factor analysis. Psychometrika, 30, 179-185. Retrieved from http://bit.ly/1oJPOJz

Hu, L., \& Bentler, P. M. (1999). Cut-off criteria for fit indexes in covariance structure analysis: Conventional criteria versus new alternatives. Structural Equation Modelling: A Multidisciplinary Journal, 6(1), 1-55.

Khaliq, A. (2001). Corporate leadership and workforce motivation in Malaysia. International Journal of Computational and Methods, 11(1). http://dx.doi.org/10.1108/eb047416

Kline, R. B. (2011). Principles and practices of structural equation modelling (3rd ed.). New York: The Guilford Publications, Inc.

Mahathir, M. (1984). Malaysia incorporated and privatisation: its rationale and purpose. In M. N. A. Ghani, B. T. H. Wang, I. K. M., Chia, \& B. Gale (Ed.), Malaysian incorporated and privatisation towards national unity (pp. 1-8). Subang Jaya: Pelanduk.

Malaysia University Portal. (2014). List of universities and colleges in Malaysia. Retrieved from: http://www.malaysiauniversity.net/

Marsh, H. W., \& Hocevar, D. (1985). Application of confirmatory factor analysis to the study of self-concept: First- and higher-order factor models and their invariance across groups. Psychological Bulletin, 97, $562-582$.

Ministry of Education Malaysia. (2001). Falsafah Pendidikan Kebangsaan, Matlamat dan Misi [National Philosophy of Education, Goal and Mission]. Putrajaya, Malaysia: Curriculum Development Centre.

Musah, M. B. (2013). Exploring the relationship between quality culture and organisational climate with workforce performance (Unpublished PhD thesis). International Islamic Unniversity Malaysia, Selangor, Malaysia.

Pallant, J. (2007). SPSS survival manual: A step by step guide to data analysis using SPSS for windows (3rd ed.). England: Open University Press, McGraw-Hill Education.

Schumacker, R. E., \& Lomax, R. G. (2004). A beginner's guide to structural equation modelling. Mahwah, n. J.: Lawrence Erlbaum Associates.

Siddiquee, N. A. (2007). Public service innovations, policy transfer and governance in the Asia-Pacific region: The Malaysian experience. Journal of Administration and Governance, 2(1). Retrieved from http://joaag.com/uploads/Siddiquee.pdf?origin =publication_detail

Steiger, J. H., \& Lind, J. M. (1980). Statistically based tests for the number of common factors. In annual meeting of the Psychometric Society, June, Iowa City, IA.

Triantafillou, P. (2002). Machinating the responsive bureaucrat: Excellent work culture in the Malaysian public sector. Asian Journal of Public Administration, 24(2), 185-209.

Uiniversiti Teknologi MARA. (2005). Our route to the present. Retrieved from http://archive.is/ROazE

Universiti Putra Malaysia. (2006). History of Universiti Putra Malaysia. Retrieved from http://www.upm.edu.my/jubliintan/sej.html 
Universiti Sains Malaysia. (2005). Buku penduan kenaikan pangkat jawatan profesor [a booklet about promotion for the post of professor]. Penang: Universiti Sains Malaysia. Retrieved from http://registry.usm.my/ portalreg/upload/borang/bukupan duan160305.pdf

Wheaton, B. (1987). Assessment of fit in overidentified models with latent variables. Sociological Methods and Research, 16, 118-154.

Wheaton, B., Muthen, B., Alwin, D. F., \& Summers, G. F. (1977). Assessing reliability and stability in panel models. Psychometrika, 54, 371-384.

\section{Appendix I}

Previous Studies on Excellent Work Culture

\begin{tabular}{|c|c|c|c|c|c|c|c|c|c|c|c|}
\hline $\begin{array}{l}\text { Author's } \\
\text { name }\end{array}$ & Year & Publication & Design & Participant & Method & $\begin{array}{l}\text { Sample } \\
\text { size }\end{array}$ & Sampling & Focus & Assumption & Gender & Reliability \\
\hline $\begin{array}{l}\text { Khaliq } \\
\text { Ahmad }\end{array}$ & 2001 & $\begin{array}{l}\text { International } \\
\text { Journal of } \\
\text { Computational } \\
\text { Methods }\end{array}$ & Qualitative & $\begin{array}{l}\text { Not } \\
\text { applicable }\end{array}$ & Conceptual & $\begin{array}{l}\text { Not } \\
\text { applicable }\end{array}$ & $\begin{array}{l}\text { Not } \\
\text { applicable }\end{array}$ & $\begin{array}{l}\text { Examining the ways } \\
\text { in which managers } \\
\text { elect to lead and } \\
\text { motivate their } \\
\text { workforce }\end{array}$ & $\begin{array}{l}\text { Not } \\
\text { applicable }\end{array}$ & $\begin{array}{l}\text { Not } \\
\text { applicable }\end{array}$ & $\begin{array}{l}\text { Not } \\
\text { applicable }\end{array}$ \\
\hline $\begin{array}{c}\text { Trianntafillou, } \\
\text { P. }\end{array}$ & 2002 & $\begin{array}{l}\text { Asian Journal } \\
\text { of Public } \\
\text { Administration }\end{array}$ & Qualitative & $\begin{array}{c}\text { Not } \\
\text { applicable }\end{array}$ & Conceptual & $\begin{array}{c}\text { Not } \\
\text { applicable }\end{array}$ & $\begin{array}{c}\text { Not } \\
\text { applicable }\end{array}$ & $\begin{array}{l}\text { Examination of the } \\
\text { bewildering array of } \\
\text { reform of the } \\
\text { Malaysian public } \\
\text { sector launched } \\
\text { since 1980's under } \\
\text { the heading of EWC }\end{array}$ & $\begin{array}{c}\text { Not } \\
\text { applicable }\end{array}$ & $\begin{array}{c}\text { Not } \\
\text { applicable }\end{array}$ & $\begin{array}{c}\text { Not } \\
\text { applicable }\end{array}$ \\
\hline $\begin{array}{l}\text { Siddiquee, N. } \\
\text { A. }\end{array}$ & 2006 & $\begin{array}{l}\text { International } \\
\text { Journal of } \\
\text { Public Sector } \\
\text { Management }\end{array}$ & Qualitative & $\begin{array}{l}\text { Not } \\
\text { applicable }\end{array}$ & Conceptual & $\begin{array}{l}\text { Not } \\
\text { applicable }\end{array}$ & $\begin{array}{l}\text { Not } \\
\text { applicable }\end{array}$ & $\begin{array}{l}\text { Examining the } \\
\text { recent changes in } \\
\text { public management } \\
\text { in Malaysia with } \\
\text { relation to New } \\
\text { Public Management } \\
\text { (NPM) and assess } \\
\text { their impacts on } \\
\text { administrative } \\
\text { performance and } \\
\text { service delivery. }\end{array}$ & $\begin{array}{l}\text { Not } \\
\text { mentioned }\end{array}$ & $\begin{array}{l}\text { Not } \\
\text { applicable }\end{array}$ & $\begin{array}{l}\text { Not } \\
\text { applicable }\end{array}$ \\
\hline $\begin{array}{l}\text { Author's } \\
\text { name }\end{array}$ & Year & Publication & Design & Participant & Method & $\begin{array}{l}\text { Sample } \\
\text { size } \\
\end{array}$ & Sampling & Focus & Assumption & Gender & Reliability \\
\hline $\begin{array}{l}\text { Siddiquee, N. } \\
\text { A. }\end{array}$ & 2007 & $\begin{array}{l}\text { Journal of } \\
\text { Administration } \\
\text { and } \\
\text { Governance }\end{array}$ & Qualitative & $\begin{array}{l}\text { Not } \\
\text { applicable }\end{array}$ & Conceptual & $\begin{array}{l}\text { Not } \\
\text { applicable }\end{array}$ & $\begin{array}{l}\text { Not } \\
\text { applicable }\end{array}$ & $\begin{array}{l}\text { Proving an } \\
\text { overview of public } \\
\text { service reform in } \\
\text { Malaysia focusing } \\
\text { on aspects of } \\
\text { innovation and } \\
\text { policy transfer }\end{array}$ & $\begin{array}{l}\text { Not } \\
\text { mentioned }\end{array}$ & $\begin{array}{l}\text { Not } \\
\text { applicable }\end{array}$ & $\begin{array}{l}\text { Not } \\
\text { applicable }\end{array}$ \\
\hline $\begin{array}{l}\text { Mohd. } \\
\text { Sahahandri } \\
\text { Gani Hamzah } \\
\text { et al. }\end{array}$ & 2009 & $\begin{array}{l}\text { European } \\
\text { Journal of } \\
\text { Social Science }\end{array}$ & Qualitative & $\begin{array}{l}\text { Not } \\
\text { applicable }\end{array}$ & Conceptual & $\begin{array}{l}\text { Not } \\
\text { applicable }\end{array}$ & $\begin{array}{l}\text { Not } \\
\text { applicable }\end{array}$ & $\begin{array}{l}\text { Examining factors } \\
\text { hindering } \\
\text { effectiveness of } \\
\text { EWC }\end{array}$ & $\begin{array}{l}\text { Not } \\
\text { mentioned }\end{array}$ & $\begin{array}{l}\text { Not } \\
\text { applicable }\end{array}$ & $\begin{array}{l}\text { Not } \\
\text { applicable }\end{array}$ \\
\hline
\end{tabular}

\section{Copyrights}

Copyright for this article is retained by the author(s), with first publication rights granted to the journal.

This is an open-access article distributed under the terms and conditions of the Creative Commons Attribution

license (http://creativecommons.org/licenses/by/3.0/). 